\section{Critério diagnóstico da doença meningocócica na Região Metropolitana de Campinas, São Paulo, Brasil}

\author{
Meningococcal disease diagnostic criteria \\ in Greater Metropolitan Campinas, \\ São Paulo State, Brazil
}

\author{
1 Faculdade de Ciências \\ Médicas, Universidade \\ Estadual de Campinas, \\ Campinas, Brasil. \\ 2 Instituto Adolfo Lutz, \\ Campinas, Brasil. \\ 3 Diretoria Regional XII, \\ Secretaria de Estado \\ de Saúde de São Paulo, \\ Campinas, Brasil. \\ 4 Secretaria Municipal \\ de Saúde de Campinas, \\ Campinas, Brasil. \\ Correspondência \\ M. R. Donalisio \\ Faculdade de Ciências \\ Médicas, Universidade \\ Estadual de Campinas. \\ C. P. 6111, Campinas, SP \\ 13083-970, Brasil. \\ donalisi@fcm.unicamp.br
}

\begin{abstract}
The aim of this article is to evaluate confirmatory criteria: culture, latex agglutination, counter immunoelectrophoresis, microscopic examination, and clinical/epidemiological criteria for cases of meningococcal disease reported in Greater Metropolitan Campinas, São Paulo State, Brazil, from 1993 to 2002 (568 cases). The following variables were also studied: clinical features, gender, age, city, hospital, case fatality, seasonality, and Neisseria meningitidis serogroup. Culture as a confirmatory criterion was the dependent variable in univariate analysis. The mean proportion of confirmatory criterion by culture was $68.7 \%$. Clinical features of meningococcal disease - meningitis without septicemia $(O R=2.87 ; C I: 1.89-4.38)$ and septicemia without meningitis (OR =0.26; CI: 0.17-0.45) - were associated with confirmation by culture. Case fatality rates were different among all diagnostic criteria. More attention should be given to etiological diagnostic confirmation in more severe cases. Diagnostic methods such as PCR may improve etiological confirmation of meningococcal disease in cases with negative cultures.
\end{abstract}

Meningococcal Infections; Neisseria meningitidis; Epidemiologic Surveillance; Meningitis; Polymerase Chain Reaction
Maria Rita Donalisio 1

Marilu Mendes Moscardini Rocha 2 Raquel Maria Ferreira Ramalheira ${ }^{3}$ Brigina Kemp 4

\section{Introdução}

A vigilância epidemiológica da doença meningocócica tem um papel fundamental no controle da transmissão. Apoiada no diagnóstico laboratorial, a vigilância é essencial para a prevenção de casos secundários, para eliminar fontes de infecção em portadores assintomáticos, além de detectar precocemente surtos e analisar o perfil das bactérias circulantes 1,2,3.

A elucidação etiológica viabiliza diagnósticos mais específicos sobre o perfil epidemiológico da doença em distintas áreas geográficas, dando maior precisão à indicação de vacinas e à sua avaliação 1,4. Porém, a capacidade do sistema em interferir na realidade epidemiológica depende da agilidade e adequação da coleta do líquido cefalorraquidiano e/ou sangue, da conservação e do transporte correto das amostras biológicas até o laboratório para a identificação de Neisseria meningitidis. Também influenciam o uso prévio de antibióticos, a sensibilidade e especificidade dos exames laboratoriais disponíveis, mesmo em condições ideais de transporte do material coletado e do adequado desempenho do laboratório 5,6,7.

Dessa forma, a avaliação dos critérios diagnósticos da doença meningocócica pode ser indicador da qualidade do Sistema de Vigilância Epidemiológica 8.

No Estado de São Paulo, no final da década de 80 , foi registrada a intensificação da circula- 
ção de Neisseria meningitidis sorogrupo B, observando-se também um aumento na proporção dos casos pelo sorogrupo C, no início dos anos 90, em várias áreas urbanas 9. Na Região Metropolitana de Campinas, São Paulo, a doença meningocócica apresentou picos de incidência com características sazonais no período de 1993 a 1998 e tendência à queda após 199710.

Dada a importância epidemiológica da doença meningocócica na região de Campinas, o objetivo deste trabalho é avaliar o critério de confirmação etiológica dos casos notificados entre 1993 e 2002, considerando a confirmação pela cultura um indicador de qualidade da vigilância epidemiológica da doença.

\section{Método}

Trata-se de estudo retrospectivo dos casos de doença meningocócica (568) notificados pelo Sistema de Vigilância Epidemiológica em parte da Região Metropolitana de Campinas nos anos de 1993 a 2002. A área delimitada para o estudo foi o Município de Campinas e outros quatro municípios vizinhos: Sumaré, Hortolândia, Paulínia e Valinhos, os quais apresentam intensa relação econômica, comercial e cultural, tratando-se de áreas conurbadas. Analisou-se a doença meningocócica considerando-se o conjunto dos municípios referidos, perfazendo ao redor de 1,4 milhões de habitantes 11.

A definição de caso da doença meningocócica se ateve aos critérios clínico, epidemiológico e/ou laboratorial registrados como critério final, seguindo ordem prioritária: cultura positiva; identificação de partículas de antígeno na contraimunoeletroforese e/ou na aglutinação pelo teste do Látex do líquido cefalorraquidiano ou soro; visualização do diplococo Gram negativo no exame bacterioscópico do líquido cefalorraquidiano ou lesões de pele; presença de petéquias associadas com quadro infeccioso ou quadro suspeito em comunicante íntimo de doença meningocócica 3 . O critério para confirmação diagnóstica por meio da cultura foi considerado padrão, seguindo as recomendações do Ministério da Saúde (MS) e da Secretaria de Estado de Saúde de São Paulo (SES-SP) 3.

O Instituto Adolfo Lutz (IAL) - Regional Campinas e Central São Paulo realizaram os exames laboratoriais para confirmação dos casos de doença meningocócica.

As informações analisadas foram coletadas das fichas de investigação do Sistema de Vigilância Epidemiológica e do banco de dados do Sistema de Informações de Agravos de Notificação (SINAN) da Direção Regional XII-Campi- nas. Foi estudado o critério diagnóstico segundo as variáveis: ano de ocorrência, sexo, idade, cidade de moradia, local de internação, forma clínica, isto é meningococcemia com e sem meningite e meningite sem meningococcemia, período do ano da ocorrência (entre abril a setembro ou outubro a março), desfecho do caso em óbito e sorogrupo de $N$. meningitidis (B, C, W135, 29E, Y, POLI).

Por meio de análise univariada, foram estudadas as variáveis acima descritas e calculadas as razões de chances (odds ratio - OR), tendo como variável dependente a confirmação do caso de doença meningocócica por meio da cultura 12.

Foram utilizados os programas de informática Epi Info-6.04 e o Programa Estatístico Logistic Procedure do SAS para a montagem do banco de dados e análises univariadas. $\mathrm{O}$ teste qui-quadrado com correção de Yates $\left(\chi^{2}\right)$ foi assumido com nível de significância $a=5 \%$. Foi analisado o estimador $O R$ para a comparação de variáveis, considerando-se $95 \%$ o intervalo de confiança (IC).

\section{Resultados}

A evolução dos critérios de confirmação etiológica da doença meningocócica notificados nos cinco municípios mostra que a cultura confirmou a maioria dos casos clínicos nos anos de 1993 a 2002, ao redor de 68,7\% (390 casos).

Não houve diferença significativa na confirmação etiológica segundo o município de residência $\left(\chi^{2}=13,24 ; p=0,35 ; G L=12\right)$, justificando a análise do conjunto dos municípios como uma área única. Foram notificados 14 indivíduos sem critério diagnóstico definido.

A Figura 1 apresenta a predominância do critério cultura com aumento no período, sendo que o critério clínico, a contraimunoeletroforese e teste do Látex mostram tendência à queda, particularmente após 1996. Observouse que, em 1996, houve diminuição no percentual de confirmação dos casos pela cultura, ao mesmo tempo em que aumentou o critério clínico e a contraimunoeletroforese.

A distribuição dos critérios de confirmação etiológica foi diversa segundo a forma clínica da doença meningocócica ( $\chi^{2}=88,44 ; \mathrm{p}<0,0001$; $\mathrm{GL}=6$ ) (Tabela 1). Os coeficientes de letalidade entre os casos confirmados pela contraimunoeletroforese e teste do Látex $(38,1 \%)$ e pela clínica/epidemiologia $(21,2 \%)$ foram maiores que os confirmados pela cultura $(15,6 \%)$ e exame bacterioscópico ( $0 \%)\left(\chi^{2}=9,31 ; \mathrm{p}=0,001 ; \mathrm{GL}=\right.$ 3). Não foi considerado o critério ignorado. 
Critério diagnóstico de confirmação da doença meningocócica. Região Metropolitana de Campinas,

São Paulo, Brasil, 1993 a 2002.

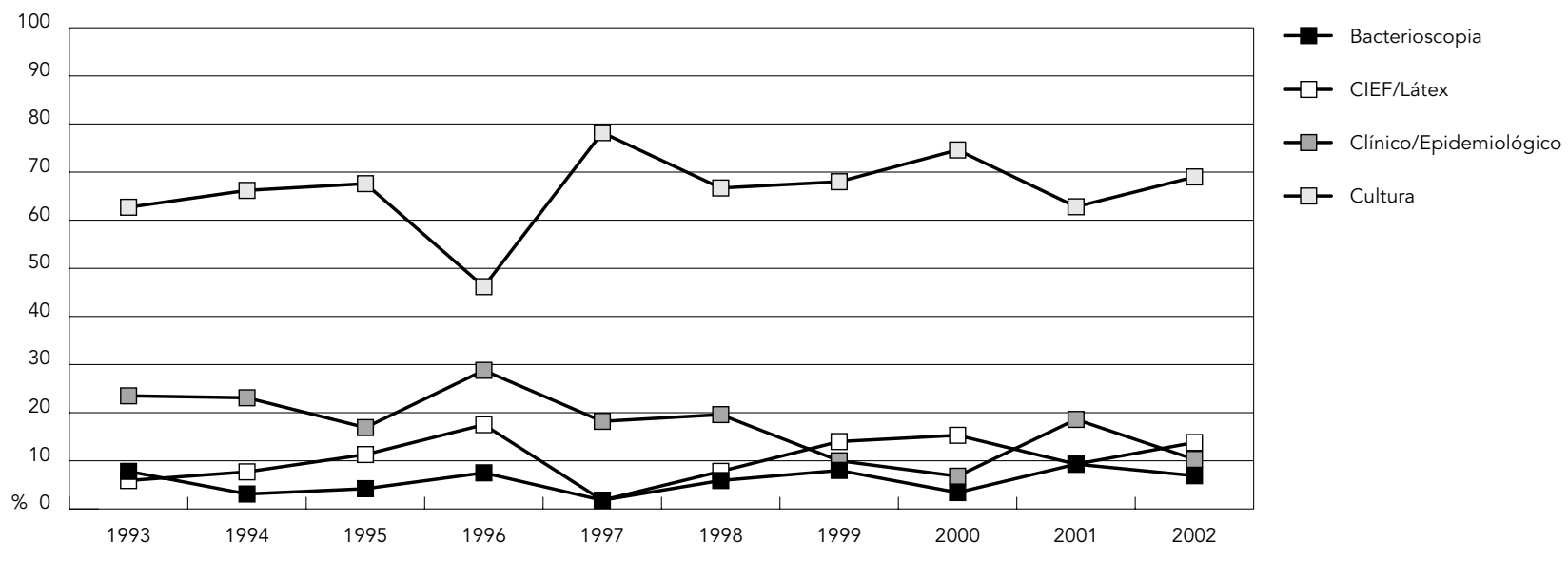

Tabela 1

Critério de confirmação diagnóstica e classificação clínica dos casos de doença meningocócica.

Região Metropolitana de Campinas, São Paulo, Brasil, 1993 a 2002.

\begin{tabular}{lcccc}
\hline Critério de confirmação & $\begin{array}{c}\text { Só meningite } \\
\mathbf{n}(\%)\end{array}$ & $\begin{array}{c}\text { Meningite }+ \\
\text { meningococcemia } \\
\mathbf{n}(\%)\end{array}$ & $\begin{array}{c}\text { Só meningococcemia } \\
\mathbf{n}(\%)\end{array}$ & $\begin{array}{c}\text { Total } \\
\mathbf{n}(\%)\end{array}$ \\
\hline Cultura & $161(83,9)$ & $192(68,6)$ & $34(43,0)$ & $387(70,2)$ \\
Bacterioscópico & $14(7,3)$ & $9(3,2)$ & $0(0,0)$ & $23(4,2)$ \\
Clínico/Epidemiológico* & $5(2,6)$ & $56(20,0)$ & $38(48,1)$ & $99(18,0)$ \\
CIEF/Látex** & $12(6,3)$ & $23(8,2)$ & $7(8,9)$ & $42(7,6)$ \\
Total & $192(34,8)$ & $280(50,9)$ & $79(14,3)$ & $551(100,0)$ \\
\hline
\end{tabular}

$\chi^{2}=88,44 ; p<0,0001 ; G L=6$ : não foram considerados os ignorados no teste qui-quadrado.

* Clínico/Epidemiológico: presença de petéquias ou caso co-primário ou secundário;

** CIEF/Látex: contraimunoeletroforese e teste do Látex do sangue e/ou LCR.

Obs.: 14 casos não tinham critério, sendo 8 sem classificação clínica.

Registrou-se diferença na forma de confirmação diagnóstica segundo local de internação. Os três grandes hospitais de referência responsáveis por $63,4 \%$ das internações de doença meningocócica apresentaram maior percentual de confirmação por cultura, enquanto o critério clínico/epidemiológico foi mais freqüente nos 25 hospitais da região (Tabela 2). Os coeficientes de letalidade foram semelhantes nos dois grupos de hospitais, respectivamente $18,0 \%$ e $16,8 \%\left(\chi^{2}=0,06 ; \mathrm{GL}=2 ; \mathrm{p}=0,81\right)$. Da mesma forma, não foi observada diferença significativa na distribuição percentual dos sorogrupos $\left(\chi^{2}=0,90 ; \mathrm{GL}=2, \mathrm{p}=0,63\right)$. Por outro lado, a forma clínica dos casos atendidos nos serviços estudados foi distinta, sendo proporcionalmente maior o percentual de meningococcemia sem meningite, $19,7 \%$ nos 25 hospitais da região, enquanto, nos três hospitais de referência, essa forma clínica foi $10,8 \%$ do total de atendimentos $\left(\chi^{2}=14,28 ; \mathrm{GL}=3 ; \mathrm{p}=0,002\right)$.

Quanto aos sorogrupos específicos: B, C e outros (Y, W13, E29 ou POLI), o critério diagnóstico não se mostrou associado a nenhum 
Tabela 2

Distribuição de critérios diagnóstico da doença meningocócica segundo local de internação. Região Metropolitana de Campinas, São Paulo, Brasil, 1993 a 2002.

\begin{tabular}{|c|c|c|}
\hline Critério & $\begin{array}{c}\text { Hospitais de referência* } \\
n(\%)\end{array}$ & $\begin{array}{c}\text { Hospitais da região** } \\
\text { n (\%) }\end{array}$ \\
\hline Cultura & $272(76,6)$ & $118(59,3)$ \\
\hline Bacterioscopia & $8(2,3)$ & $15(7,5)$ \\
\hline Clínico/Epidemiológico*** & $51(14,4)$ & $48(24,1)$ \\
\hline 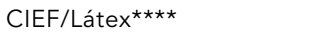 & $24(6,7)$ & $18(9,1)$ \\
\hline Total & $355(100,0)$ & $199(100,0)$ \\
\hline
\end{tabular}

$\chi^{2}=21,68 ; G L=3 ; p<0,0001$.

Total de casos analisados foi 554, somente os com critério diagnóstico

e local de internação registrados.

* 3 grandes hospitais em Campinas: Hospital das Clínicas da Unicamp

Hospital Celso Pierro PUCC e Hospital Municipal Mário Gatti;

$\star \star 25$ hospitais gerais da região metropolitana estudada;

$\star \star \star$ Clínico/Epidemiológico: presença de petéquias ou caso co-primário

ou secundário;

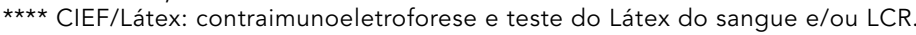

deles $\left(\chi^{2}=5,98 ; p=0,43 ; G L=6\right)$. Nesta análise, foram considerados somente os casos que tiveram possibilidades de sorogrupagem e com critério definido $(\mathrm{n}=426)$ (Tabela 3$)$.

Tendo-se o critério cultura como variável dependente, as variáveis analisadas: sexo, período do ano de ocorrência, sorogrupo, idade, município de residência e internação não se apresentaram significativas ( $p>0,25)$ (Tabela 4).

\section{Discussão}

Houve um aumento do critério cultura na confirmação etiológica da doença meningocócica de 1993 a 2002, na Região Metropolitana de Campinas, sugerindo uma melhora na investigação dos casos e da qualidade do Sistema de Vigilância Epidemiológica, particularmente no final dos anos 90. A disponibilização dos meios de cultura, frascos para coleta de líquido cefalorraquidiano e sangue, e soro para contraimunoeletroforese e teste do Látex ("kit meningi-

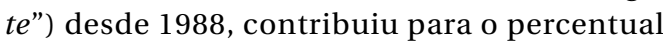
crescente do critério cultura para confirmação dos casos; além da capacitação para a descentralização da semeadura do material biológico precocemente. Também a montagem de núcleos de vigilância epidemiológica hospitalares, particularmente nos hospitais de referência, facilitou a investigação completa dos casos, recuperando, muitas vezes, materiais biológicos para confirmação etiológica.

Embora seja apontada, na literatura, a tendência de diminuição da confirmação pela cultura pelo uso cada vez mais precoce de antimi- crobianos e redução da indicação de punção lombar 13, ainda são muitos os casos de doença meningocócica com possibilidade de confirmação por meio da melhora da atuação da vigilância epidemiológica no país.

Os dados não sugerem variações sazonais do critério de investigação dos casos por meio da cultura, embora esse comportamento não tenha sido avaliado por meio de modelos estatísticos apropriados. Em estudo sobre a tendência dos casos de doença meningocócica na região, a sazonalidade foi notificada nas últimas décadas na região 10 .

$\mathrm{Na}$ análise univariada, os casos de doença meningocócica confirmados pela cultura do líquido cefalorraquidiano ou sangue mostraram-se associados à forma clínica da doença, porém não com a letalidade. A idade do paciente, o sexo, a época do ano, o sorogrupo não interferiram na possibilidade de confirmar o caso por meio da cultura do líquido cefalorraquidiano ou sangue (Tabela 4). Porém, a confirmação por meio da cultura foi maior nos três hospitais mencionados $\left(\chi^{2}=21,68\right.$; GL $=3$; $\mathrm{p}<$ $0,0001)$, onde possivelmente as rotinas de coleta e de processamento das amostras para diagnóstico da doença meningocócica estejam mais bem estabelecidas. A letalidade por local de internação não se apresentou diferente entre os grupos de hospitais, não obstante, esperam-se os mais elevados coeficientes nos serviços de maior complexidade. Esse fato pode estar relacionado com um significativo percentual de casos de meningococcemia sem meningites atendidos pelos 25 outros hospitais da região $(19,7 \%)$. Os perfis de atendimento, da gravidade dos casos e da capacidade diagnóstica dos diversos hospitais podem ser analisados com maior detalhamento segundo interesses do Sistema de Saúde regional.

O ano 1996 foi singular, a queda do critério cultura foi simultânea ao aumento da clínica e da bacterioscopia para confirmação dos casos. Naquele ano, foram registrados, também, pico de incidência da doença, aumento percentual de casos graves, como a meningococcemia sem meningite, e maior letalidade, comparando-se com anos anteriores 10 .

A investigação diagnóstica é mais completa nos casos clínicos menos graves. Esse fato é esperado já que a meningite sem septicemia tem melhor evolução, havendo maior tempo hábil para coleta adequada de exames, comparados com as outras formas clínicas. Além disso, tradicionalmente frente à suspeita clínica de meningite, o líquido cefalorraquidiano é colhido e encaminhado para cultura mais facilmente que o sangue. O líquido cefalorraquidiano sem si- 
Critério diagnóstico e sorogrupos da Neisseria meningitidis dos casos de doença meningocócica notificados. Região Metropolitana de Campinas, São Paulo, Brasil, 1993 a 2002.

\begin{tabular}{|c|c|c|c|c|}
\hline Critério & $\begin{array}{c}\text { B } \\
n(\%)\end{array}$ & $\begin{array}{c}\text { Sorogrupo } \\
\mathrm{C} \\
\mathrm{n}(\%)\end{array}$ & $\begin{array}{c}\text { Outros* } \\
\text { n (\%) }\end{array}$ & $\begin{array}{l}\text { Total } \\
\text { n (\%) }\end{array}$ \\
\hline Cultura & $241(87,6)$ & $121(89,6)$ & $14(87,5)$ & $342(82,0)$ \\
\hline CIEF/Látex** & $29(10,5)$ & $11(8,1)$ & $2(12,5)$ & $42(9,9)$ \\
\hline Clínico/Epidemiológico*** & $5(1,8)$ & $1(0,7)$ & $0(0,0)$ & $6(1,4)$ \\
\hline Bacterioscopia & $0(0,0)$ & $2(1,5)$ & $0(0,0)$ & $2(0,5)$ \\
\hline Total & $275(64,6)$ & $135(31,7)$ & $16(3,8)$ & $426(100,0)$ \\
\hline
\end{tabular}

$\chi^{2}=5,98 ; p=0,43 ; G L=6$.

* Outros sorogrupos foram: 29E, W135, Y, POLI;

** CIEF/Látex: contraimunoeletroforese e teste do Látex do sangue e/ou LCR:

*** Clínico/Epidemiológico: presença de petéquias ou caso co-primário ou secundário.

Obs.: Foram analisados somente os casos sorogrupados e com critério definido $(n=426)$.

nais de meningite e a maior gravidade em pacientes com septicemia, muitas vezes, dificultam a investigação etiológica mais detalhada, já que a condução clínica do caso prescinde da confirmação do sorogrupo e sorotipo-subtipo da $N$. meningitidis.

Há que ressaltar que, nos casos de evolução fulminante, muitas vezes, pouca atenção é dada à investigação etiológica diante do choque séptico. Além da possibilidade de casos não confirmados serem, na verdade, quadros bacterianos ou virais de outras etiologias 14 .

A diferença na letalidade, segundo os critérios clínicos, reforça a hipótese de que os casos de meningite sem septicemia apresentam evolução mais favorável e maior freqüência de investigação completa por meio da cultura Enquanto os casos definidos pelo critério clínico são sempre casos mais graves, pois são definidos pela presença de púrpura, um sinal de má evolução clínica. A contraimunoeletroforese e o teste do Látex são critérios de confirmação utilizados com maior freqüência nos casos de evolução rápida, na impossibilidade de realização ou positivação da cultura.

Portanto, maior atenção na confirmação etiológica da doença meningocócica deve ser dada, particularmente, aos casos mais graves da doença, nos quais a confirmação etiológica tem sido mais precária.

O acompanhamento do critério diagnóstico da doença meningocócica pode ser importante indicador para a avaliação da qualidade do Sistema de Vigilância Epidemiológica, no que se refere à sua agilidade, à capacidade das equipes no monitoramento e à articulação intersetorial assistência-laboratório. Esses parâmetros po-
Tabela 4

Fatores relacionados à cultura como critério diagnóstico da doença meningocócica. Região Metropolitana de Campinas, São Paulo, Brasil, 1993 a 2002.

\begin{tabular}{lcc}
\hline Variáveis & OR* & IC95\% \\
\hline Meningite sem meningococcemia & 2,87 & $1,89-4,38$ \\
Menigococcemia sem meningite & 0,27 & $0,17-0,45$ \\
Óbito & 0,68 & $0,44-1,07$ \\
Idade & 1,00 & $0,99-1,02$ \\
Sexo & 0,94 & $0,66-1,34$ \\
& & $0,77-1,57$ \\
Período do ano** & 1,09 & $0,45-1,58$ \\
Sorogrupo B & 0,84 & $0,63-2,35$ \\
Sorogrupo C & 1,22 & $0,21-4,21$ \\
Outros & 0,93 & \\
\hline
\end{tabular}

* OR = odds ratio da análise univariada;

** de abril a setembro.

dem indicar a necessidade de revisão dos "caminhos" das amostras biológicas desde o momento da coleta até seu processamento no laboratório. Dessa forma, é possível investigar os pontos de maior vulnerabilidade que explicam a não positivação da cultura. A determinação da etiologia da doença meningocócica também possibilita o acompanhamento da sensibilidade de bactérias a antimicrobianos 15 .

O monitoramento da circulação de sorogrupos, sorotipos e subtipos de $N$. meningitidis dá subsídios para a utilização de imunobiológicos, ampliando a compreensão da epidemiologia da doença 1 . A falta do diagnóstico etiológico preciso tem sido importante problema da 
vigilância epidemiológica da doença meningocócica, dificultando a detecção de novos clones da $N$. meningitidis e melhor acompanhamento dos já conhecidos.

Vários pesquisadores sugerem a utilização de técnicas complementares para aumentar a capacidade de identificação etiológica dos casos de doença meningocócica e da detecção de linhagens de $N$. meningitidis. Entre os exames laboratoriais sugeridos, estão as técnicas de amplificação do DNA pela reação em cadeia de polimerase (PCR) no líquido cefalorraquidiano ou sangue 16,17,18,19. Podem aumentar a confirmação laboratorial em mais de 50,0\% de amostras com cultura negativas 20 , ampliando a capacidade de identificação de amostras contaminadas ou com bactérias mortas devido às más condições de refrigeração e transporte. Essas técnicas têm sido indicadas na vigilância de meningites bacterianas em áreas remotas para compensar a precariedade ou a falta de laboratórios clínicos locais 21,22.

Em muitas regiões do país, as ações de vigilância das meningites ainda encontram dificuldades básicas, como em outras doenças. Po-

\section{Resumo}

Foi estudado o critério de confirmação etiológica: cultura, clínico, teste do Látex e contraimunoeletroforese, exame bacterioscópico e clínico/epidemiológico dos 568 casos notificados de doença meningocócica na Região Metropolitana de Campinas, São Paulo, Brasil, de 1993 a 2002. Foram analisadas as variáveis: forma clínica, idade, sexo, local de moradia e internação, época do ano de ocorrência, letalidade e sorogrupo da Neisseria meningitidis. Confirmaram-se, pela cultura, $68,7 \%$ dos casos. A letalidade foi diferente de acordo com o critério de confirmação da doença. As formas clínicas: meningite sem meningococcemia (OR $=2,87$; IC: 1,89 $4,38)$ e a meningococcemia sem meningite $(O R=0,26$; IC: 0,17-0,45) mostraram-se associadas com o critério cultura. Maior atenção à confirmação diagnóstica deve ser dada aos casos mais severos. A utilização do teste da reação em cadeia de polimerase pode ser útil para aumentar a capacidade da confirmação etiológica da doença meningocócica em casos de culturas negativas.

Infecções Meningocócicas; Neisseria meningitidis; $\mathrm{Vi}$ gilância Epidemiológica; Meningite; Reação em Cadeia da Polimerase rém, em áreas que contam com boa retaguarda laboratorial da vigilância epidemiológica, a utilização do PCR pode ser de grande utilidade como técnica complementar às tradicionais, a ser utilizada nos casos de cultura negativa, como, por exemplo, diante de uso prévio de antibióticos ou dificuldades operacionais.

Embora o grande desafio da vigilância epidemiológica seja investir na estruturação de equipes e treinamento em centenas de municípios ainda com condições precárias de trabalho, técnicas diagnósticas mais sofisticadas podem ser disponibilizadas em laboratórios de referência, onde já existem recursos e pessoal treinado. Se utilizadas com racionalidade e critérios restritos, podem aumentar a capacidade do sistema de diagnosticar, com maior precisão, situações epidemiológicas específicas e facilitar o controle da doença.

Essa estratégia não dispensa as equipes de vigilância de continuarem o árduo trabalho de garantir a investigação clínica e epidemiológica adequada dos casos, por parte das infinitas portas de entrada do sistema de saúde.

\section{Colaboradores}

M. R. Donalisio propôs o artigo e participou do planejamento, da análise, da discussão e da redação do texto. M. M. M. Rocha participou do planejamento, da análise, da discussão e da redação do texto. R. M. F. Ramalheira participou do planejamento, da discussão, elaborou o banco de dados e o gráfico, e revisou os dados. B. Kemp participou do planejamento e da discussão e revisou os dados e o texto. 


\section{Referências}

1. Barroso DE, Carvalho DM, Nogueira AS, Solari CA. Doença meningocócica: epidemiologia e controle dos casos secundários. Rev Saúde Pública 1998; 32:89-97.

2. Melles CEA, Landgraf IM, Faracol ML, Bascardi MNB. Valor da bacterioscopia, cultura e imunoeletroforese cruzada no diagnóstico das meningites bacterianas. Rev Inst Adolfo Lutz 1989; 49: 61-7.

3. Fundação Nacional de Saúde. Guia de vigilância epidemiológica. v. II. Brasília: Ministério da Saúde; 2002.

4. Noronha CP, Baran M, Nicolai CCA, Azevedo MB, Bernardes ATO, Monteiro GTR, et al. Epidemiologia da doença meningocócica na cidade do Rio de Janeiro: modificações após vacinação contra os sorogrupos B e C. Cad Saúde Pública 1997; 13:295-303.

5. Rocha MMM, Esper MRNR, Neme SN, Medeiros MIC, Silva RRF, Arreaza ALV, et al. Avaliação do diagnóstico laboratorial da doença meningocócica pelos laboratórios regionais do IAL. Rev Inst Adolfo Lutz 1999; 58:35-41.

6. Ragunathan L, Ramsay M, Borrow R, Guiver M, Gray S, Kaczmarski EB. Clinical features, laboratory findings and management of meningococcal meningitis in England and Wales, report of a 1997 surveys. J Infect 2000; 40:74-9.

7. Kemp B, Rocha MMM, Iverson LB. Avaliação do diagnóstico laboratorial da doença meningocócica em pacientes internados em um hospital sentinela, 1991. Rev Inst Adolfo Lutz 1998; 57:13-9.

8. Centers for Disease Control and Prevention. Guidelines for evaluating surveillance systems. MMWR Morb Mortal Wkly Rep 1988; 37 Suppl 5:1-18.

9. Sacchi CT, Lemos APS, Camargo MCC, Whitney AM, Melles CEA, Solari CA, et al. Meningococcal disease caused by Neisseria meningitidis serogroup B serotype 4 in São Paulo, Brazil, 1990 to 1996. Rev Inst Med Trop Sao Paulo 1998; 40:113-7.

10. Donalisio MRC, Kemp B, Rocha MMM, Ramalheira RMF. Letalidade na epidemiologia da doença meningocócica: estudo na região de Campinas SP, 1993 a 1998. Rev Saúde Pública 2000; 34:58995.

11. Fundação Sistema Estadual de Análise de Dados. Sistema de documentação sobre população no Brasil: informações dos municípios paulistas 2002. http://www.seade.gov.br/cgi-bin/lingcv98/ spd_01.ksh (acessado em 13/Jul/2004).

12. Medronho RA, Carvalho DM, Block KV, Luiz RR, Werneck GL. Epidemiologia. São Paulo: Atheneu; 2002.
13. Begg N, Cartwright KVA, Cohen J, Kaczmarski EB, Innes JA, Leen CL, et al. Consensus statement on diagnosis, investigation, treatment and prevention of acute bacterial meningitis in immunocompetent adults - British Infection Society Working Party. J Infect 1999; 39:1-15.

14. Sigurdardóttir B, Bjornsson OM, Jónsdóttir E, Erlendsdóttir H, Gudmundsson S. Acute bacterial meningitis in adults - a 20-year overview. Arch Intern Med 1997; 157:425-30.

15. Tapsall JW, Shultz T, Simnios E, Munro R, Mercer J, Porrit R, et al. Surveillance of antibiotic ressitence in invasive isolates of Neisseria meningitidis. Australia 1994-1999. Pathology 2001; 33:359-61.

16. Clark SC, Reid J, Thom L, Denham BC, Edward GF. Laboratory confirmation of meningococcal disease in Scotland, 1993-9. J Clin Pathol 2002; 55:32-6.

17. Corless CE, Guiver M, Borrow R, Edward-Jones V, Fox AJ, Kaczmarski EB. Simultaneous detection of Neisseria meningitides, Haemophilus influenzae and Streptococcus pneumoniae in suspected cases of meningitis and septicemia using realtime PCR. J Clin Microbiol 2001; 39:1553-8.

18. Gray SJ, Sobanski MA, Kaczmarski EB, Guiver M, Marsh WJ, Borrow R, et al. Ultrasound-enhanced latex immunoagglutination and PCR as complementary methods for non-culture based confirmation of meningococcal disease. J Clin Microbiol 1999; 37:1780-97.

19. Porritt RJ, Mercer JL, Munro R. Detection and serogroup determination of Neisseria meningitidis in CSF by polymerase chain reaction (PCR). Pathology 2000; 32:42-5.

20. Newcombe J, Cartwright K, Palmer WH, McFadden J. PCR of peripheral blood for diagnosis of meningococcal disease. J Clin Microbiol 1996; 34:1637-40.

21. Sidikou F, Djibo S, Taha MK, Alonso JM, Djibo A, Kairo KK, et al. Polymerase chain reaction assay and bacterial meningitis surveillance in remote areas, Niger. Emerg Infect Dis 2003; 19:1486-8.

22. Pollard AJ, Probe G, Trombley C, Castell A, Whitehead S, Bigham JM, et al. Evaluation of a diagnostic polymerase chain reaction assay for Neisseria meningitides in North America and field experience during an outbreak. Arch Pathol Lab Med 2002; 126:1209-15.

Recebido em 04/Fev/2004

Versão final reapresentada em 08/Jun/2004 Aprovado em 25/Jun/2004 